\title{
The Regional Small Hydropower Generated Energy Forecasting Method
}

\author{
Shuai Han, Lijuan Qin, XiQiao Lin and Xu Yan
}

Guangxi Power Grid Electric Power Research Institute, 6-2 Minzhu Street, Nanning, Guangxi 530023, China.

Keywords Small hydropower station, Meteorological factor, Rainfall, Multiple regression fitting

\begin{abstract}
To improve forecasting accuracy of the generated energy of regional small hydropower stations, it is proposed a forecasting method of regional small hydropower generation considering the cumulative effect of rainfall.In this paper, the meteorological data was classified by using decision tree firstly. Then through the in-depth analysis of the output law of small hydropower stations, the generated energy forecasting model was set up using the method of multiple regression fitting that considering the rainfall effect. Finally, the corrected model is established to correct the predicted results that considering accumulative effect of rainfall.
\end{abstract}

\section{INTRODUCTION}

As an important clean renewable energy, small hydroelectric power plants have following features. The installed capacity is small, the construction period is short, the output is closely related to weather, and they are widespread throughout the area with abundant water resources.With the installment capacity of small hydroelectric power plants growing, its proportion in total electrical generating capacity is rising. Due to the small reservoir capacity and no energy storage, rainfall greatly influences the generating capacity of small hydroelectric power plants, that is, the generating capacity of small hydroelectric power plants depends on the rainfall and then the wholesale electricity is affected indirectly.

A great deal of research work on the influence of meteorological factors on the load forecasting curve has been conducted by scholars around the world[1-6], but there are still several aspects that should be considered.

(1) The complexity and variability of weather ,including the weather changes continuously in time,and the weather might abruptly change at the same time.

(2) Dual nature of the influence of weather on load. One hand, the effect of real-time weather changes on the load. On the other hand, the effect of meteorological cumulative effect on the load.

For the sake of those problems mentioned above, a forecasting method based on meteorological decision tree was proposed ,and the monthly generated energy of small hydropower stations was predicted by using the method in this paper.

\section{GENERATED ENERGY FORECASTING OF SMALL HYDROPOWER STATIONS CONSIDERING RAINFALL}

\subsection{LAWS ANALYSIS OF THE OUTPUT OF SMALL HYDROPOWER STATIONS}

Small hydropower stations in China are run-of-river power stations, so the regulation capability is poor, and the output depends on natural flow of rivers and fall. Due to that small hydropower stations are mainly distributed in mountainous regions and most have no storage capacity or small capacity, there is obvious correlativity between generated energy of small hydropower stations and rainfall.It is the 
precondition for performing load forecasting task well in regions with small hydropower stations to get exact generated energy change rules of small hydropower stations. However, the generated energy of small hydropower stations is very indeterminate, and its regularity is often unsatisfactory. Under conditions of no rain, rain and continual heavy rain, generated energy curves of small hydropower stations were given in reference [7].Due to the complicated delayed effects of rainfall, current monthly accumulated rainfall would influence the hydropower output of next month.

\subsection{CORRELATION BETWEEN WEATHER AND GENERATED ENERGY}

Taking small hydropower stations in a certain area as an example, correlations between actual monthly generated energy and accumulated rainfall and that between actual monthly generated energy and temperature between 2010-2015 from May to October are calculated . The results are shown in Figure 1.

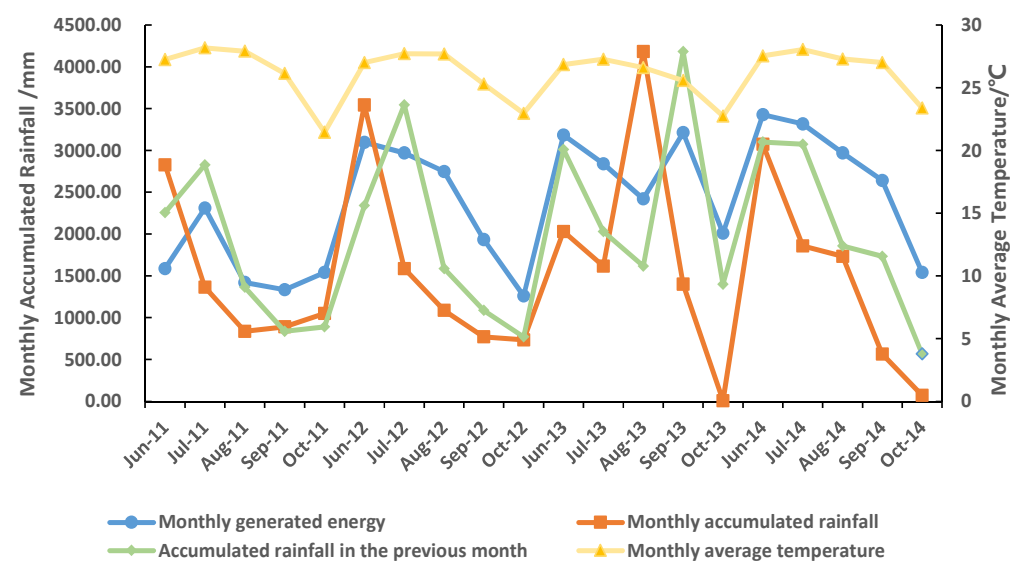

Figure 1. Monthly generated energy variation with weather in a certain area

It can be seen from Figure 1 that, temperature and rainfall have obvious positive correlations with monthly generated energy of small hydropower stations, and monthly generated energy are influenced by the whole fluctuation trend of accumulated rainfall in the previous month , monthly accumulated rainfall and monthly average temperature. As accumulated rainfall in the previous month rose, monthly generated energy of small hydropower stations would rise, meanwhile it would fluctuate influenced by monthly rainfall and temperature. If $L$ is daily maximum load, $X_{i}$ is anyone of meteorological variables, then the formula of correlation between monthly generated energy and anyone of meteorological variables is as follow[1].

$$
r=\frac{\sum_{t=1}^{n}\left(L_{t}-\bar{L}_{t}\right)\left(X_{i t}-\bar{X}_{i t}\right)}{\sqrt{\sum_{i=t}^{n}\left(L_{t}-\bar{L}_{t}\right)^{2}} \sqrt{\sum_{i=t}^{n}\left(X_{i t}-\bar{X}_{i t}\right)^{2}}}
$$

To find the relationship that monthly generated energy varies with historical generated energy.The correlation between actual monthly generated energy and generated energy in the previous month is also calculated. 
TABLE I . CORRELATIONS BETWEEN ACTUAL MONTHLY GENERATED ENERGY OF SMALL HYDROPOWER STATIONS AND METEOROLOGICAL FACTOR

\begin{tabular}{|cc|}
\hline Meteorological Factor & Correlation Coefficient \\
\hline Monthly Accumulated Rainfall & 0.49 \\
Accumulated Rainfall in The Previous Month & 0.71 \\
Monthly Average Temperature & 0.44 \\
Generated Energy in The Previous Month & 0.58 \\
\hline
\end{tabular}

It could be seen from Table I the correlation between actual monthly generated energy of small hydropower stations and accumulated rainfall in the previous month is the largest one, and the following one is that with generated energy in the previous month. Therefore, monthly cumulative rainfall of the month before, monthly cumulative rainfall and previous month generated energy are chosen as the three key influence factors for modeling.

\subsection{GENERATED ENERGY FORECASTING MODEL OF SMALL HYDROPOWER STATIONS}

Historical rainfall and the output data were used to establish generated energy forecasting model of small hydropower stations. The steps are as follows.

$$
W_{m f}=f\left(W_{m h}, R_{m h}, R_{m f}\right)
$$

Here, $W_{m f}$ is the predicted monthly generated energy of small hydropower stations, $W_{m h}$ is the monthly generated energy of previous month, $R_{m h}$ is the monthly rainfall of previous month in this region, $R_{m f}$ is the predicted monthly rainfall.

Due to that several independent variables were involved in this model, the output forecasting model of small hydropower stations would be established using multivariate linear regression and multivariate nonlinear regression.

Model was set up using multivariate linear regression as follow.

$$
W_{m f}=a_{1} W_{m h}+a_{2} R_{m h}+a_{3} R_{m f}+\varepsilon
$$

Here, $a_{1}, a_{2}, a_{3}$ are the coefficients of ternary linear regression, which could be calculated in Matlab. $\varepsilon$ is random error term, which is included in $W_{m f}$ but cannot be explained by the linear relation of the first three independent variables.

\subsection{CORRECTED MODEL CONSIDERING ACCUMULATIVE EFFECT}

The cumulativity of rainfall were analyze above, so the accuracy of prediction model could be improved considering the influence of rainfall on the generated energy of small hydropower stations.

If the basic forecasting model in subsection 2.3 is correct, the change of monthly rainfall could cause the prediction error of the model. In this subsection, corrected model was established using rainfall increment of two straight months and the error between actual value and the predicted generated energy of small hydropower stations.

Firstly, the rainfall increment of two straight months is calculated as follow.

$$
\Delta R_{i}=R_{i}-R_{i-1}
$$

Here, $R_{i}$ is the monthly accumulated rainfall of the month to be predicted. $R_{i-1}$ is the monthly accumulated rainfall of the previous month. $\Delta R_{i}$ is the increment of monthly accumulated rainfall of the two months. Based on the error between actual value and the monthly output value of small hydropower stations, the error caused by rainfall increment is calculated as follow. 


$$
\Delta W_{i}=W_{r i}-W_{i}
$$

Here, $W_{i}$ is the monthly output value of small hydropower stations obtained by multivariate regression model. $W_{r i}$ is the actual output value of small hydropower stations. $\Delta W_{i}$ is the error between predicted value and actual value of the ith month.

Considering accumulative effect of rainfall, the corrected output forecasting model of small hydropower stations could be set up using multivariate linear regression formula as follow.

$$
\Delta \hat{W}_{i}=\mu \Delta R_{i}+\eta
$$

Here, $\mu$ and $\eta$ are the correction coefficients. $\Delta W_{i}$ is the predicted correction considering accumulative effect of rainfall. The corrected output forecasting model of small hydropower stations could be achieved by adding formula (6) to (3).

\section{OVERALL PREDICTION PROCESS}

The proposed regional small hydropower generated energy forecasting method considering the cumulative effect of rainfall , and its overall prediction process is shown as follow. Firstly, the weather and generated energy data are acquired and processed. The weather data is classified by using decision tree, and the weather condition of the day predicted is estimated. Secondly, the load characteristic of small hydropower stations is thoroughly studied considering their actual power output, the main weather factors with influence on small hydropower stations are analyzed and the basic power forecasting model is established considering rainfall effect. For the cumulative effects of rainfall, the generated energy forecasting model of small hydropower stations is corrected considering monthly rainfall increment. Through the weather estimation of the day predicted by using the classification algorithm of decision tree, the basic forecasting model combines the modified model to predict the monthly generated energy of small hydropower stations.

\section{EXPERIMENTS AND ANALYSIS}

The proposed method was used to predict the generated energy of small hydropower stations in a certain area , where the period is from June to October in 2015 corresponding to the flood period in summer, and the experimental results were analyzed in this section.

\subsection{WEATHER SITUATION ANALYSIS}

The rainfall in the region is plentiful in summer, and the generated energy of small hydropower stations varies with monthly accumulated total rainfall as shown in Figure 2 as follow. 


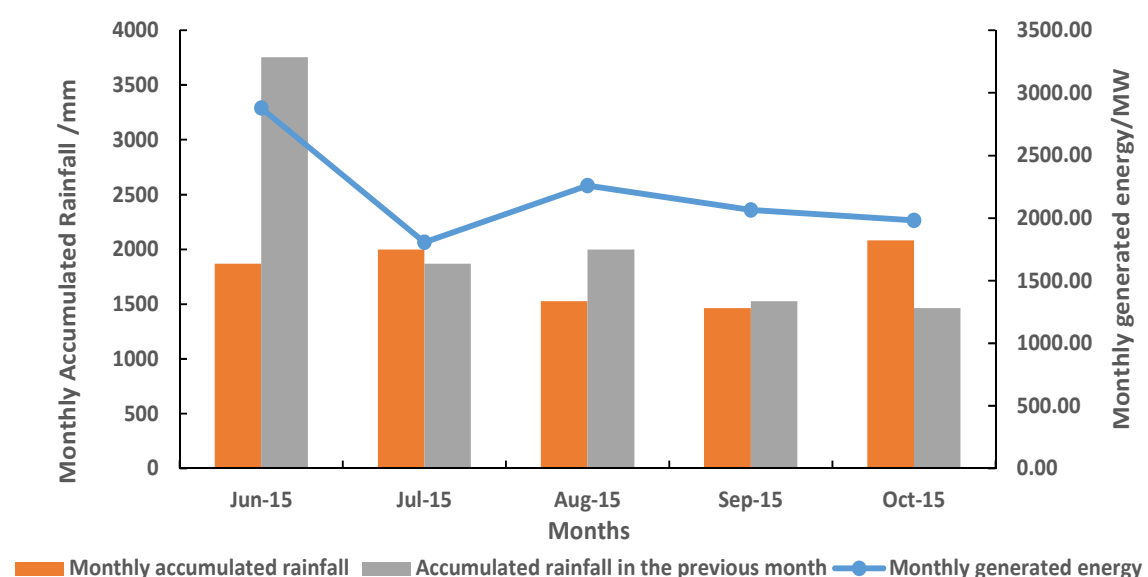

Figure 2. The change of monthly weather in the summer of 2015

\subsection{POWER GENERATION FORECASTING OF SMALL HYDROPOWER STATIONS}

The power generation forecasting of small hydropower stations was modeled with historical data from 2010 to 2014 and error analysis was conducted. Then Formula (3) was chosen to set up basic forecasting model. The model parameters are shown as follow, which were calculated based on historical output data.

$$
W_{m f}=0.54 W_{m h}+0.13 R_{m h}+0.33 R_{m f}+130.59
$$

The power generation forecasting of small hydropower stations from June to October in 2015 were predicted and corrected using Formula (3) and (6). The predicted errors of maximum load before correction are shown in Table II. The predicted errors of maximum load after correction are shown in Table III.

TABLE II. PREDICTION RESULTS OF MAXIMUM GENERATED ENERGY OF SMALL HYDROPOWER STATIONS FROM JUNE TO OCTOBER IN 2015

\begin{tabular}{ccccc}
\hline \multirow{2}{*}{ Month } & $\begin{array}{c}\text { Regional monthly capacity } \\
\text { (MWh) }\end{array}$ & $\begin{array}{c}\text { Basic predicted value } \\
\text { (MWh) }\end{array}$ & Error & Error rate \\
\hline Jun. 2015 & 2014.79 & 1333.89 & -680.90 & $-33.8 \%$ \\
Jul. 2015 & 1263.96 & 1803.93 & 539.97 & $42.7 \%$ \\
Aug. 2015 & 1581.59 & 1305.61 & -275.99 & $-17.5 \%$ \\
Sep. 2015 & 1444.41 & 1417.19 & -27.22 & $-1.9 \%$ \\
Oct.2015 & 1387.32 & 1480.09 & 92.78 & $6.7 \%$ \\
\hline
\end{tabular}

TABLE III. PREDICTION ERROR OF MAXIMUM GENERATED ENERGY AFTER CORRECTION

\begin{tabular}{ccccc}
\hline \multirow{2}{*}{ Month } & $\begin{array}{c}\text { Regional monthly capacity } \\
\text { (MWh) }\end{array}$ & $\begin{array}{c}\text { Corrected predicted value } \\
\text { (MWh) }\end{array}$ & Error & Error rate \\
\hline Jun. 2015 & 2014.79 & 2014.41 & -0.38 & $0.0 \%$ \\
Jul. 2015 & 1263.96 & 1370.94 & 106.97 & $8.5 \%$ \\
Aug. 2015 & 1581.59 & 1430.55 & -151.05 & $-9.6 \%$ \\
Sep. 2015 & 1444.41 & 1380.04 & -64.37 & $-4.5 \%$ \\
Oct.2015 & 1387.32 & 1281.25 & -106.06 & $-7.6 \%$ \\
\hline
\end{tabular}


It can be seen from the prediction results that, the prediction error of maximum output of small hydropower stations after corrected are less and no more than $10 \%$.

\section{Conclusions}

The small hydropower generated energy forecasting method considering the cumulative effect of rainfall has been proposed in this paper. It is based on several indexes obtained through comprehensive research to establish multiple linear basic forecasting model with correction. Based on the above results, it can be known that this method takes the key factors influencing the generated energy of small hydropower stations into account, establishes basic forecasting model with less error and preliminarily corrects prediction results, which further reduces the error.

This work is supported by staff technical innovation project of Guangxi Power Grid Co., Ltd (2016-262)

\section{References}

[1] T Hong, M Gui, ME Baran, HL Willis. 2010. "Modeling and Forecasting Hourly Electric Load by Multiple Linear Regression with Interactions,” presented at 2010 IEEE Power and Energy Society General Meeting, July 25-29, 2010.

[2] LEI Shaolan, SUN Caixin, ZHOU Quan and ZHANG Xiaoxing. 2006. "The Research of Local Linear Model of Short-Term Electrical Load on Multivariate Time Series,” Proceedings of the CSEE, 26(2): 25-29.

[3] Song Kyung-Bin. 2006. "Hybrid Load Forecasting Method with Analysis of Temperature Sensitivities,” IEEE Transactions on Power Systems, 21(2): 869-876.

[4] JIAO Runhai, SU Chenjun, LIN Biying and MO Ruifang. 2013. "Short-Term Load Forecasting by Grey Model With Weather Factor-Based Correction,” Power System Technology, 37(3): 720-725.

[5] ZHANG Ben, SHI Peiran and JIANG Chao. 2013. "Impact of meteorological factors on summer load characteristics of Beijing-Tianjin-Tangshan Power Grid,” Electric Power Automation Equipment, 33(12): 140-144.

[6] Xu Q, He D, Zhang N and C Kang. 2015. "A Short-Term Wind Power Forecasting Approach With Adjustment of Numerical Weather Prediction Input by Data Mining," IEEE Transactions on Sustainable Energy, 6(4):1283-1291.

[7] Senjyu, T. Mandai, P. Uezato, K. and Funabashi T. 2004. "Next day load curve forecasting using recurrent neural network structure," presented at IET Proceedings-Generation Transmission and Distribution, January 14, 2004. 